\title{
BMJ Open Socioeconomic and geographical variation in general practitioner consultations for allergic rhinitis in England, 2003-2014: an observational study
}

\author{
Daniel Todkill, ${ }^{1,2}$ Paul Loveridge, ${ }^{3}$ Alex James Elliot, ${ }^{3,4}$ Roger Morbey, ${ }^{3}$ \\ Simon de Lusignan,, ${ }^{5,6}$ Obaghe Edeghere, ${ }^{1,3}$ Gillian Smith ${ }^{3,4}$
}

To cite: Todkill $D$, Loveridge $P$, Elliot AJ, et al. Socioeconomic and geographical variation in general practitioner consultations for allergic rhinitis in England, 2003-2014: an observational study. BMJ Open 2017;7:e017038. doi:10.1136/ bmjopen-2017-017038

- Prepublication history and additional material are available. To view these files, please visit the journal online (http://dx.doi. org/10.1136/bmjopen-2017017038).

Received 28 March 2017 Revised 26 June 2017 Accepted 7 July 2017

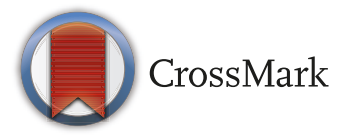

For numbered affiliations see end of article.

Correspondence to

Dr Daniel Todkill;

d.todkill@warwick.ac.uk

\section{ABSTRACT}

Objective Allergic rhinitis (AR) is a global health problem, potentially impacting individuals' sleep, work and social life. We aimed to use a surveillance network of general practitioners (GPs) to describe the epidemiology of AR consultations in England.

Setting A large GP surveillance network covering approximately $53 \%$ of the English population. Methods GP consultations for AR across England between 30 December 2002 and 31 December 2014 were analysed. Using more granular data available between 2 April 2012 and 31 December 2014 rates and rate ratios (RR) of AR were further analysed in different age groups, gender, rural-urban classification and index of multiple deprivation score quintile of location of GP.

Results The mean weekly rate for AR consultations was 19.8 consultations per 100000 GP registered patients (range 1.13-207), with a regular peak occurring during June (weeks 24-26), and a smaller peak during April. Between 1 April 2012 and 31 December 2014, the highest mean daily rates of consultations per 100000 were: in age group $5-14$ years (rate $=8.02$, $\mathrm{RR} 6.65,95 \% \mathrm{Cl} 6.38$ to 6.93); females (rate=4.57, RR $1.1295 \% \mathrm{Cl} 1.12$ to 1.13 ); persons registered at a GP in the most socioeconomically deprived quintile local authority (rate=5.69, RR 1.48, $95 \% \mathrm{Cl} 1.47$ to 1.49 ) or in an urban area with major conurbation (rate=5.91, RR $1.78,95 \% \mathrm{Cl} 1.69$ to 1.87 ). Conclusions AR rates were higher in those aged 5-14 years, females and in urban and socioeconomically deprived areas. This needs to be viewed in the context of this study's limitations but should be considered in health promotion and service planning.

\section{INTRODUCTION}

Allergic rhinitis (AR) is a symptomatic disorder of the nose induced by an IgE-mediated inflammation after allergen exposure of the membranes lining the nose. ${ }^{1}$ AR is a global health problem affecting an estimated 500 million people worldwide. ${ }^{2}$ In the UK, self-reported prevalence among adults has been estimated at 21.8\% (95\% CI

\section{Strengths and limitations of this study}

- Our study provides a pragmatic measure of the burden of allergic rhinitis consultations in general practice settings in England, over a 12-year period.

- The study sample size was large, equivalent to $53 \%$ of the England population (approximately 35 million registered patients).

- Some analyses used aggregated data at different population levels, raising the possibility of ecological fallacy if any inferences are made about individuals based on the observed group level correlations and averages.

- We were unable to gather individual level data on location of residence, so we used general practitioner practice location as a proxy, potentially introducing measurement bias but we are unclear in which direction this may have biased our results (if at all).

19.8 to 23.9 ), and based on physician diagnosis at $13.2 \%$ (95\% CI 11.6 to 14.9$){ }^{3} \mathrm{AR}$ can impact on individual's sleep, ${ }^{4}$ performance at school $^{5}$ or work ${ }^{6}$ and social life ${ }^{7}$ and has substantial financial costs to society; in Sweden, cost to the economy has been estimated at approximately $€ 2.7$ billion annually. ${ }^{8}$

AR has a multifactorial aetiology, characterised by interaction between genetic and environmental factors. Known risk factors for exacerbations include outdoor allergens (pollens and moulds), and indoor allergens (mites, animal dander, insects and indoor moulds). ${ }^{1}$ An association between AR and asthma exists, with a high proportion of individuals with allergic and non-allergic asthma also having AR. ${ }^{9}$ Admission to hospital with acute asthma is strongly associated with the combination of sensitisation, 
exposure to sensitising allergens and viral infection. ${ }^{10}$ There is also evidence for an association between AR and three major air pollutants (namely $\mathrm{PM}_{10}, \mathrm{SO}_{2}$ and $\left.\mathrm{NO}_{2}\right) .{ }^{11}$

Public Health England (PHE) coordinates a national programme of syndromic surveillance. The suite of systems includes a general practitioner in-hours syndromic surveillance system (GPIH), which monitors a network of general practitioners (GPs) across England covering approximately 53\% of the English population, ${ }^{12}$ with good regional coverage (in London there is coverage in 30 of the 31 administrative districts). ${ }^{13}$ In addition, the Royal College of General Practitioners (RCGP) coordinate the Weekly Returns Service, a sentinel GP network monitoring a number of morbidity indicators (including AR consultations) since 1967. ${ }^{1415}$

The characteristics of cases of AR who present to GPs remain to be fully elucidated. There have been studies which have shown AR prevalence is higher in urban than rural areas ${ }^{16}{ }^{17}$; however, the relationship between $\mathrm{AR}$ and socioeconomic status is uncertain. AR was originally considered a disease of affluence, ${ }^{18}$ with a number of studies highlighting a positive association between AR and socioeconomic position, ${ }^{19}{ }^{20}$ but there has been a call for more research into the relationship. ${ }^{2}$

The aim of this paper was to describe the epidemiology of AR in order to improve our understanding of the burden of disease and characteristics of cases in England. Our objectives were to describe the pattern of GP consultations for AR across England between 30 December 2002 and 31 December 2014 and using more granular data between weeks 142012 and week 52 2014 to estimate the rates of AR in different age groups, genders and by rural-urban classification and socioeconomic deprivation.

\section{METHODS}

\section{Study design}

This was a retrospective, observational descriptive analysis of in-hour GP consultations for AR in GP practices across England providing data to the PHE GPIH system. The study population was all persons who presented to GPs participating in the GPIH between 30 December 2002 and 31 December 2014. A case of AR was defined as a GP consultation episode where the GP assigned a Read code (the classification system currently used in the UK practice $)^{21}$ consistent with AR. In the UK, the clinical diagnosis of allergic rhinitis is usually established based on presenting symptoms and medical history; in particular, the presence or absence of antecedent triggers. The code list included those for allergic rhinitis, allergic rhinosinutis and hay fever (5-Byte Read codes H17; Read clinical terms V.3 XE0Y5). English general practice is a registration-based system (patients register with a single practice) with most practices computerised since 2004, thus ensuring an accurate denominator for this study. ${ }^{22}$

\section{Data sources}

\section{GP consultation data}

Study period I was defined as including weekly national GP consultation rates for AR between 30 December 2002 and 31 December 2014. Two sources of GP morbidity data were used to maximise the time period available for temporal analysis. Between 30 December 2002 and 1 April 2012, GP consultation data provided by the RCGP GP Surveillance system were used: the RCGP sentinel GP network consists of approximately 100 nationally representative practices located across England. ${ }^{14}{ }^{15}$ Between 2 April 2012 and 31 December 2014, data from the PHE GPIH were used: the GPIH system comprises a network of approximately 4000 practices across England. ${ }^{12}$

Study period II was defined as including weekly national GP consultation rates for AR between 2 April 2012 and 31 December 2014. During this period, a subset of GPIH data containing more granular information were analysed allowing breakdown by age band and gender at upper tier local authority (UTLA) and national level.

\section{Index of multiple deprivation ranking}

The English Index of Multiple Deprivation (IMD) 2015 is the official measure of relative deprivation for small areas: these small areas are lower-layer super output areas (LSOA) ${ }^{23}$ The IMD combines seven domains of deprivation, chosen to cover a range of economic, social and housing indicators into a single score for each upper-tier local authority level. We assigned IMD score and quintile based on the location (UTLA) of the GP practice.

\section{Rural-urban classification}

The Office of National Statistics rural-urban classification is used to distinguish rural and urban areas, and categorises UTLAs on a six-point scale from rural to urban based on the share of their population resident in a rural area. ${ }^{24}$ The classification identifies areas as either largely rural (rural including hub towns $\geq 80 \%$ ), mainly rural (rural including hub towns 50\%-79\%), urban with significant rural (rural including hub towns 26\%-49\%), urban with city and town, urban with minor conurbation or urban with major conurbation. The rural-urban status of cases was assigned based on the location (UTLA) of the GP practice rather than the individual's location of residence.

\section{Data analysis}

The mean weekly AR consultation rate and 95\% CIs per 100000 population across England were calculated for individual years during study period I using the count of AR consultations as the numerator and weekly GP registered population as the denominator. Consultation rates were adjusted for public holidays (when GP practices are traditionally closed) using methods described elsewhere. ${ }^{25}$ During study period II, the daily AR rate per 100000 population was calculated using daily GP registered population as the denominator; bank holidays and weekends were removed from this analysis. 
Time series graphs were used to visualise secular trends and seasonality of the weekly national consultation rates for AR during study period I. The mean annual rate of AR consultations and range of weekly rates of consultations per year was calculated and the peak week identified for AR consultations in each year.

We undertook subgroup analyses by age group, gender, IMD quintile of upper-tier local authority and rural-urban classification of UTLA using the GPIH data during study period II. Bank holidays and weekends were removed to reflect GP practices being closed outside of usual working hours. Rates and rate ratios (RR) were calculated to provide a measure of relative difference between groups. One of the two providers of GPIH data had lower coverage than the other, but more granular data, which allowed for directly standardised rates (DSR; standardised by age and sex) to be calculated using the European Standard Population 2013 for IMD quintile of upper-tier local authority and gender. DSRs were not calculated for rural-urban classifications due to low coverage in rural areas for this data source.

\section{RESULTS}

During study period I, there were 824195 AR consultations. The mean weekly rate of AR consultations was 19.8 per 100000 GP registered patients (range 1.13-207 per 100000 ). The magnitude of the mean weekly rates of consultations varied between years (see online supplementary table A) and there was no long-term trend observed based on visual inspection of the time series (figure 1).
A seasonal pattern was observed as all years showed at least two distinct peaks in consultations; the earlier peak occurring between weeks 13 and 21 (mode $=20)$ and the second peak between weeks 24 and $26($ mode $=25)$. With the exception of 2011, the second peak was consistently larger than the first peak (table 1).

During study period II, there were 748372 AR consultations coded as AR to the GPIH, and a mean daily rate of 4.3 AR consultations per 100000 GP registered patients (range $0.57-33.20$ ). There were statistically significant differences in rate of GP consultations for AR across age groups. Persons aged 5-14 years had the highest AR consultation rate (8.02 per 100000 consultations). This was six times higher than persons aged $<1$ year (RR 6.65; $95 \%$ CI 6.38 to 6.93 ; table 2).

The mean daily AR consultation rate was $12 \%$ higher among females compared with males (4.57 vs 4.07 per 100000 GP registered population, RR 1.12, 95\% CI 1.12 to 1.13$)$.

The mean daily AR consultation rate in UTLA areas ranged between 0.36 (Stoke-on-Trent) to 10.5 (Tower Hamlets) per 100000 GP registered population in the UTLA areas in England (figure 2).

The mean AR consultation rate in the most socioeconomically deprived UTLAs (quintile 1) was 5.69 per 100000 GP registered population compared with 3.85 per 100000 in the least deprived (quintile 5). This difference was statistically significant (RR 1.48, 95\% CI 1.47 to 1.49). This difference was also observed in the DSRs (see online supplementary table B).

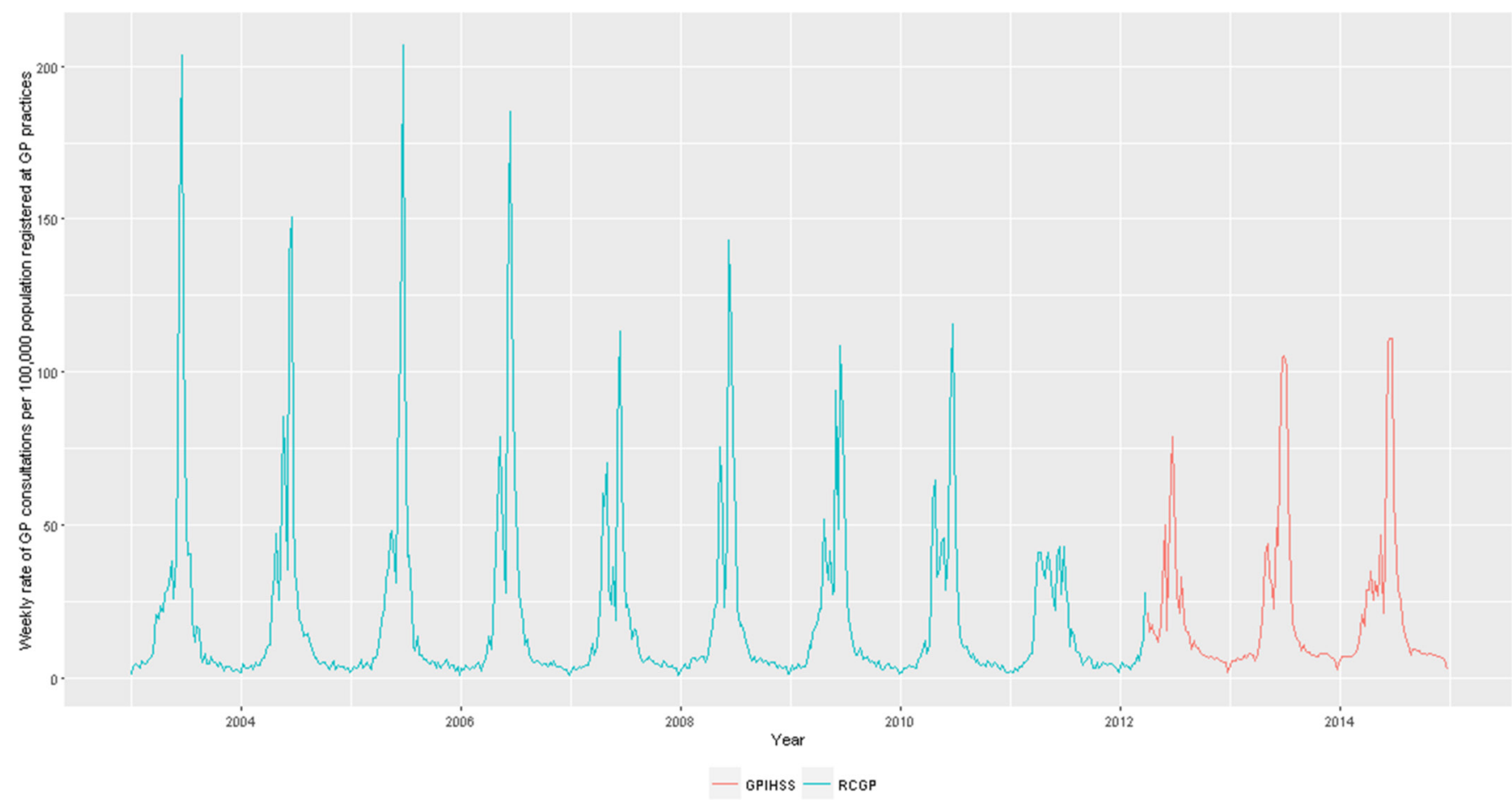

Figure 1 Weekly rates of consultations for allergic rhinitis to participating general practitioners (GPs) contributing to the Royal College of General Practitioners (RCGP) and general practitioner in-hours (GPIH) syndromic surveillance systems per 100000 GP registered population, England, week 12003 to week 522014. 
Table 1 Allergic rhinitis (AR) consultation rates by peak week (first and second peaks), England, 2003-2014

\begin{tabular}{|c|c|c|c|c|}
\hline & First AR peak & & Second AR pe & \\
\hline Year & Week number & Rate per 100 000* & Week number & Rate per $100000^{\star}$ \\
\hline 2003 & 25 & 203.4 & 20 & 38.2 \\
\hline 2004 & 25 & 150.9 & 21 & 85.7 \\
\hline 2005 & 25 & 207 & 20 & 48.2 \\
\hline 2006 & 24 & 185 & 19 & 79.1 \\
\hline 2007 & 24 & 113.4 & 18 & 70.2 \\
\hline 2008 & 24 & 143 & 20 & 75.8 \\
\hline 2009 & 25 & 108.5 & 17 & 52 \\
\hline 2010 & 25 & 115.9 & 17 & 64.6 \\
\hline 2011 & 17 & 54.275 & 26 & 43 \\
\hline 2012 & 26 & 79.11 & 13 & 27.9 \\
\hline 2013 & 27 & 105.44 & 19 & 43.9 \\
\hline 2014 & 26 & 111.17 & 16 & 34.81 \\
\hline
\end{tabular}

${ }^{*}$ Rate per 100000 GP registered population.

Statistically significant differences were observed in the UTLAs classified as mainly rural (2.91 AR consultations per 100000 GP registered population) compared with those classified as urban areas with major conurbations (5.91 AR consultations per $100000 \mathrm{GP}$ registered population, RR $1.78,95 \%$ CI 1.69 to 1.87 ).

\section{DISCUSSION}

There was a clear and consistent pattern of annual peaks in AR GP consultations during June that was preceded by an earlier peak of lower magnitude, usually during April. These seasonal peaks appeared to coincide with tree and grass pollen seasons, which have been previously defined for the UK summer. ${ }^{26}$ Over the study period, there was no sustained long-term trend identified in the rate of AR consultations in primary care.

The mean daily AR consultation rate was highest in females and in persons aged $5-14$ years, followed by those aged 15-44 years. We observed a deprivation gradient, with higher AR consultation rates in GP practices located in the most socioeconomically deprived areas. High AR consultation rates were also observed in GP practices located in areas classified as 'urban areas major conurbation'.

There were a number of limitations to our study: first, we undertook our analysis using data aggregated at the UTLA and LSOA levels. This raises the possibility of ecological fallacy if any inferences are made about individuals based on the observed group level correlations and averages.

Second, we were unable to gather individual level data on location of residence; instead, we used GP practice location as a proxy. This may have introduced some measurement bias, but we are unclear in which direction this would have biased our results (if at all).
Third, study period I used two different data sources: the RCGP between 30 December 2002 and 1 April 2012 and the GPIH between 2 April 2012 and 31 December 2014. Both of these systems have different coverage across England. Although on the national level, both systems' coverage was sufficient to identify trends, we cannot rule out completely that the absence of an upward or downward trend is not a result of the change in systems observed. However, analysis of data from one provider covering the period 2002-2012 illustrated a lack of trend, thereby supporting our overall conclusions.

Fourth, we were unable to differentiate between the different clinical types of AR as we only had access to aggregated read-code data, we were unable to undertake stratified analyses nor build a regression model to fully explore the nature of the relationship between our outcome and predictor variables and any statistical interaction between the predictor variables.

Finally, as we only had access to aggregated data, we could not examine the potential confounding effect of variables that were measured at an individual level such as obesity, ${ }^{27}$ exposure to air pollutants ${ }^{28}$ and ethnicity ${ }^{18}$ and have been postulated as risk factors for AR consultations.

Despite these limitations, our findings are considered robust as it provides a pragmatic measure of the burden of AR consultations in general practice settings in England. The improvement in GP coverage in the GPIH during study period II means the estimates are more robust and accurate. Our findings remained unchanged using the smaller dataset and adjusting for differences in the demographic profile of the different UTLAs.

Exploration of GP prescriptions for antihistamines, low-dose steroid nasal sprays and anti-allergic eye-drops might provide further insights and further work is needed to explore the contribution of specific predictor variables 
Table 2 Mean daily allergic rhinitis (AR) consultation rates per 100000 GP registered population by age group, gender and IMD quintile and rural-urban classification of cases' general practitioner and rate ratio

\begin{tabular}{|c|c|c|c|}
\hline Age group (years) & Rate per $100000^{*}$ & Rate ratio $(95 \% \mathrm{Cl})$ & \\
\hline$<1$ & 1.21 & 1.00 & - \\
\hline 1 to 4 & 3.25 & 2.69 & $(2.58 \text { to } 2.81)^{\star \star \star}$ \\
\hline 5 to 14 & 8.02 & 6.65 & $(6.38 \text { to } 6.93)^{\star \star *}$ \\
\hline 15 to 44 & 5.12 & 4.24 & $(4.07 \text { to } 4.42)^{\star \star \star}$ \\
\hline 45 to 64 & 2.91 & 2.41 & $(2.31 \text { to } 2.51)^{\star \star \star}$ \\
\hline 65 to 74 & 2.79 & 2.31 & $(2.21 \text { to } 2.41)^{\star \star \star}$ \\
\hline $75+$ & 2.10 & 1.74 & $(1.66 \text { to } 1.81)^{\star \star \star}$ \\
\hline \multicolumn{4}{|l|}{ Gender } \\
\hline Male & 4.07 & 1.00 & - \\
\hline Female & 4.57 & 1.12 & $(1.12 \text { to } 1.13)^{\star \star \star}$ \\
\hline \multicolumn{4}{|l|}{ IMD quintile } \\
\hline 1 & 5.69 & 1.48 & $(1.47 \text { to } 1.49)^{\star \star \star}$ \\
\hline 2 & 4.55 & 1.18 & $(1.17 \text { to } 1.19)^{\star \star \star}$ \\
\hline 3 & 3.96 & 1.03 & $(1.02 \text { to } 1.04)^{\star \star \star}$ \\
\hline 4 & 3.87 & 1.00 & $(1.00 \text { to } 1.01)^{\star \star \star}$ \\
\hline 5 & 3.85 & 1.00 & - \\
\hline \multicolumn{4}{|l|}{ Rural-urban classification } \\
\hline Mainly rural & 2.91 & 1.00 & - \\
\hline Largely rural & 3.35 & 1.15 & $(1.09 \text { to } 1.21)^{\star \star \star}$ \\
\hline Urban with significant rural & 3.74 & 1.28 & $(1.22 \text { to } 1.35)^{\star \star \star}$ \\
\hline Urban with city and town & 4.07 & 1.40 & $(1.33 \text { to } 1.47)^{\star \star \star}$ \\
\hline $\begin{array}{l}\text { Urban with minor } \\
\text { conurbation }\end{array}$ & 3.87 & 1.33 & $(1.26 \text { to } 1.40)^{\star \star \star}$ \\
\hline $\begin{array}{l}\text { Urban with major } \\
\text { conurbation }\end{array}$ & 5.19 & 1.78 & $(1.69 \text { to } 1.87)^{\star \star \star}$ \\
\hline
\end{tabular}

$95 \% \mathrm{Cls}$ in parentheses.

IMD quintile 1 is most socioeconomically deprived.

*Mean daily rate of consultations for allergic rhinitis per 100000 GP registered population. ${ }^{* * *} \mathrm{p}<0.001$.

IMD, Index of Multiple Deprivation.

such as pollen, air pollutants and other meteorological factors to the burden of AR consultations in primary care.

Population surveys providing estimates of AR prevalence in different subgroups were most commonly identified in a search of the literature. In contrast, this current study describes the burden of AR consultations in the general practice setting, thus providing an estimate of the workload in general practices that can be attributed to AR. Our study showed an age and gender distribution that contrasts with that reported in the literature, where boys are at a higher risk until puberty, when this situation reverses thus resulting in equal risk in males and females in adulthood. ${ }^{1}$ AR can be self-managed using over-the-counter (OTC) remedies and this means that a proportion of cases may not present at healthcare facilities, thus leading to the underestimation of the burden of disease. The influence of geographic and temporal variation in healthcare seeking behaviour, use of OTC remedies and severity of AR episodes may explain the differences in the burden of AR found in our study and those reported in the literature.

The direction of the deprivation gradient observed in our study was not consistently observed in other studies. In some studies, AR prevalence was found to be higher among persons residing in the least socioeconomically deprived areas. ${ }^{19} 20$ A longitudinal study conducted in Sweden found the association with social class changed over time, with steep increases in AR in those with low socioeconomic status, ${ }^{29}$ while a further recent study observed an association between AR and low parental educational levels. $^{30}$

The observed differences in AR consultations by deprivation raises a number of unanswered questions about health inequalities that should be explored in further research and translated into clinical practice. The primary question for further research should be focused on whether health inequality in the burden of AR might be a feature of its underlying incidence/prevalence, or 

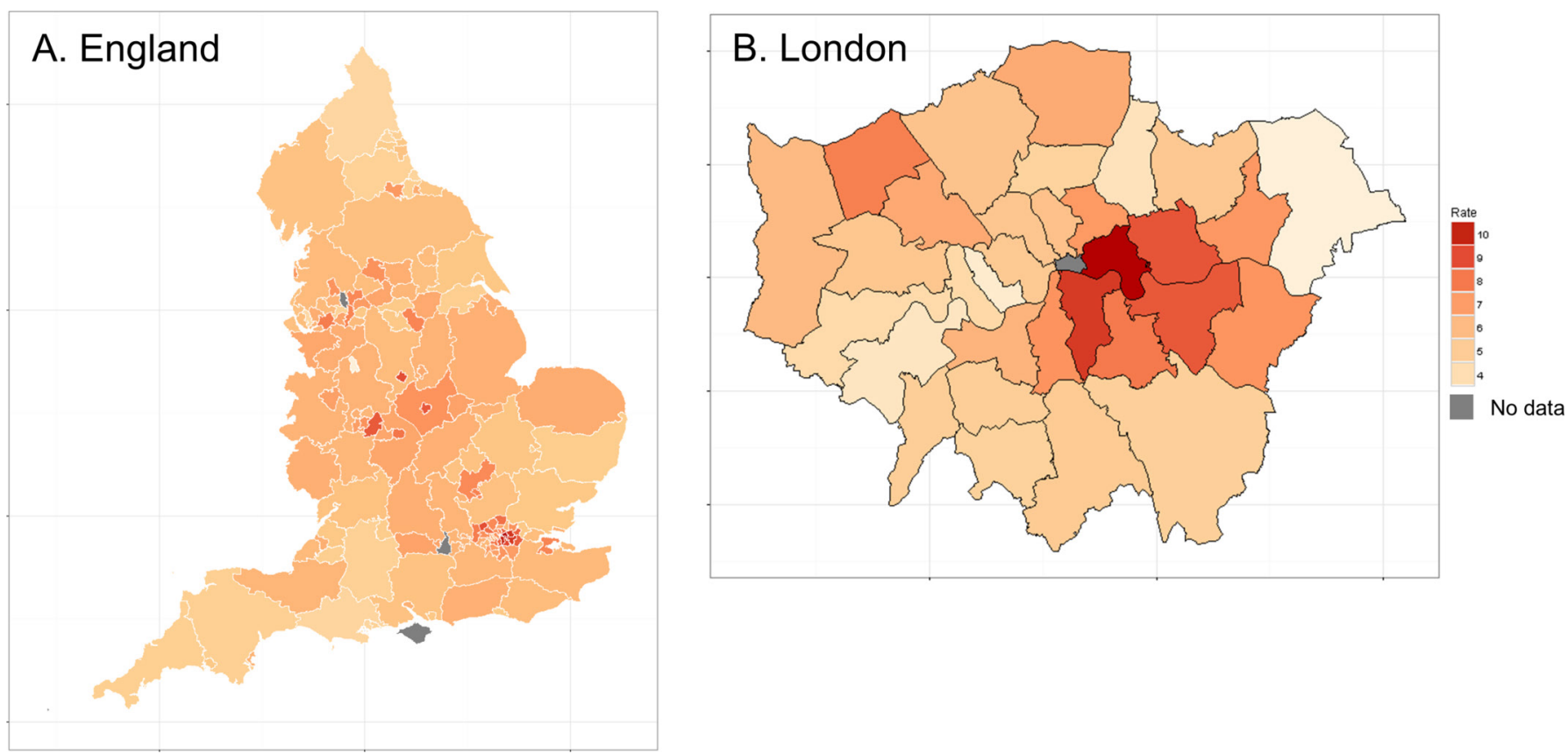

Figure 2 Choropleth map showing mean daily AR consultation rate per 100000 GP registered population in upper-tier local authority areas for (A) England and (B) London, 2 April 2012 and 31 December 2014.

is it caused by differences in health-seeking behaviours and/or healthcare access. The answer to this question(s) may contribute to shaping public health interventions (eg, seasonal health promotion messages) to lower morbidity. Free prescriptions for children may also be a contributory factor to why the reported burden of AR is higher in more socially deprived areas and should be investigated further.

The finding of a higher burden of AR in urban areas is consistent with other studies. ${ }^{16}$ A number of explanations have been adduced for this observation, including the possible protective effect of ingestion of non-pasteurised milk in infancy in rural areas, ${ }^{31}$ the interaction between traffic-related air pollutants and allergens and the antigenicity of these pollutants ${ }^{32}$ and a decreased exposure to allergens among city dwellers leading to lower tolerance to pollens. ${ }^{33}$ In addition, some tree taxa have been used extensively as ornamental plants in cities; such urban planning may be contributory to changing pollen trends in cities. ${ }^{34}$ It is also possible that unknown confounders are present that may explain this relationship. ${ }^{2}$

The absence of a long-term increasing or decreasing trend in GP consultations for AR is consistent with an earlier study which used RCGP data from practices in Darlington, Derby and London (cities in England) between 1981 and $1992 .{ }^{16}$ The study observed two distinct peaks annually and the authors concluded that the peaks coincided with weeks with the highest grass pollen counts. This study also reported an age distribution that was similar to that observed in our study.

The relationship between the different taxa of pollen and GP consultations for AR is likely to be complex, and might be further elucidated through time series methodologies.

We have demonstrated that AR remains an important burden on GP consultations, and that the peaks in consultations have a consistent seasonal pattern. The observed variation by demographic subgroups, deprivation quintile and rural-urban characteristic need to be taken into account by clinicians, public health practitioners and commissioners of healthcare services when assessing the health needs of their population and in planning proactive health promotion campaigns.

\section{Author affiliations}

${ }^{1}$ Field Epidemiology Service, National Infection Service, Public Health England, Birmingham, UK

${ }^{2}$ Health Services Division, Warwick Medical School, University of Warwick, Coventry, UK

${ }^{3}$ Real-time Syndromic Surveillance, National Infection Service, Public Health England, Birmingham, UK

${ }^{4}$ NIHR Health Protection Research Unit, Emergency Preparedness and Response, London, UK

${ }^{5}$ Department of Clinical \& Experimental Medicine, University of Surrey, Surrey, UK ${ }^{6}$ Research and Surveillance Centre, Royal College of General Practitioners, London, England

Acknowledgements The authors would like to thank the PHE ReSST team for technical excellence and support; TPP, Research0ne and the Systm0ne GP practices contributing to this surveillance system; the University of Nottingham, ClinRisk and the contribution of EMIS and EMIS practices (V.1 of the QSurveillance database); practices and their patients involved in the Royal College of General Practitioners (RCGP) Research and Surveillance Centre (RSC) sentinel network who allowed their data to be shared with the RCGP RSC. The authors acknowledge the support of the National Institute for Health Research Health Protection Research Unit (NIHR HPRU) in Emergency Preparedness and Response at King's College London in partnership with Public Health England.

Contributors DT, AE, OE and GS developed the idea for the project. DT and PL completed the analysis of data; RM provided statistical support and SDL provided 
support with RCGP data. DT drafted the initial manuscript; all authors commented on and revised subsequent versions and approved the final submitted manuscript.

Funding This work did not receive any external funding and was supported through core surveillance funding by Public Health England. AJE and GS are supported by the National Institute for Health Research Health Protection Research Unit (NIHR HPRU) in Emergency Preparedness and Response at King's College London in partnership with PHE. The views expressed are those of the author(s) and not necessarily those of the NHS, the NIHR, the Department of Health or PHE.

Competing interests None declared.

Provenance and peer review Not commissioned; externally peer reviewed.

Data sharing statement № additional data are available.

Open Access This is an Open Access article distributed in accordance with the Creative Commons Attribution Non Commercial (CC BY-NC 4.0) license, which permits others to distribute, remix, adapt, build upon this work non-commercially, and license their derivative works on different terms, provided the original work is properly cited and the use is non-commercial. See: http://creativecommons.org/ licenses/by-nc/4.0/

(C) Article author(s) (or their employer(s) unless otherwise stated in the text of the article) 2017. All rights reserved. No commercial use is permitted unless otherwise expressly granted.

\section{REFERENCES}

1. Bousquet J, Van Cauwenberge P, Khaltaev N, et al.Allergic rhinitis and its impact on asthma. J Allergy Clin Immunol 2001;108:S14 7-S334.

2. Bousquet J, Khaltaev N, Cruz AA, et al. Allergic rhinitis and its impact on asthma (ARIA). Allergy 2008;63:8-160.

3. Bauchau V, Durham SR. Prevalence and rate of diagnosis of allergic rhinitis in Europe. Eur Respir J 2004;24:758-64.

4. Craig TJ, McCann JL, Gurevich F, et al. The correlation between allergic rhinitis and sleep disturbance. J Allergy Clin Immunol 2004;114:S139-S145.

5. Tanner L, Reilly M, Meltzer E, et al. Effect of fexofenadine $\mathrm{HCl}$ on quality of life and work, classroom, and daily activity impairment in patients with seasonal allergic rhinitis. American Journal of Managed Care 1999;5:S235-S47.

6. Kessler RC, Almeida DM, Berglund P, et al. Pollen and mold exposure impairs the work performance of employees with allergic rhinitis. Ann Allergy Asthma Immunol 2001;87:289-95.

7. Leynaert B, Neukirch $\mathrm{C}$, Liard R, et al. Quality of life in allergic rhinitis and asthma. A population-based study of young adults. Am J Respir Crit Care Med 2000;162:1391-6.

8. Hellgren J, Cervin A, Nordling S, et al. Allergic rhinitis and the common cold--high cost to society. Allergy 2010;65:776-83.

9. Leynaert B, Neukirch C, Kony S, et al. Association between asthma and rhinitis according to atopic sensitization in a population-based study. J Allergy Clin Immunol 2004;113:86-93.

10. Murray CS, Simpson A, Custovic A, et al. Allergens, viruses, and asthma exacerbations. Proc Am Thorac Soc 2004;1:99-104.

11. Zhang F, Wang W, Lv J, et al. Time-series studies on air pollution and daily outpatient visits for allergic rhinitis in Beijing, China. Sci Total Environ 2011;409:2486-92.

12. Public Health England. Real time syndromic surveillance team website. 2015 https://www.govuk/government/collections/ syndromic-surveillance-systems-and-analyses

13. Harcourt SE, Fletcher J, Loveridge P, et al. Developing a new syndromic surveillance system for the London 2012 Olympic and Paralympic Games. Epidemiol Infect 2012;140:2152-6.
14. Fleming DM. Weekly returns service of the Royal College of General Practitioners. Commun Dis Public Health 1999;2:96-100.

15. Correa A, Hinton W, McGovern A, et al. Royal College of General Practitioners Research and Surveillance Centre (RCGP RSC) sentinel network: a cohort profile. BMJ Open 2016;6:e011092.

16. Ross AM, Fleming DM. Incidence of allergic rhinitis in general practice, 1981-92. BMJ 1994;308:897-900.

17. Priftis KN, Anthracopoulos MB, Nikolaou-Papanagiotou A, et al. Increased sensitization in urban vs. rural environment--rural protection or an urban living effect? Pediatr Allergy Immunol 2007;18:209-16.

18. Chen JT, Krieger N, Van Den Eeden SK, et al. Different slopes for different folks: socioeconomic and racial/Ethnic disparities in Asthma and Hay fever among 173,859 U.S. men and women. Environ Health Perspect 2001;110:211-6.

19. Forastiere F, Agabiti N, Corbo GM, et al. Socioeconomic status, number of siblings, and respiratory infections in early life as determinants of atopy in children. Epidemiology 1997;8:566-70.

20. Svanes C, Jarvis D, Chinn S, et al. Childhood environment and adult atopy: results from the European Community Respiratory Health Survey. J Allergy Clin Immunol 1999;103:415-20.

21. de Lusignan S. Codes, classifications, terminologies and nomenclatures: definition, development and application in practice. Inform Prim Care 2005;13:65-9.

22. de Lusignan $\mathrm{S}$, van Weel $\mathrm{C}$. The use of routinely collected computer data for research in primary care: opportunities and challenges. Fam Pract 2006;23:253-63.

23. Department of Communities and Local Government. HM Government. The indices of deprivation. 2015 https://www.gov.uk/ government/statistics/english-indices-of-deprivation-2015

24. Department for Environment, Food and Rural Affairs. HM Government. 2011 Rural-Urban Classification of Local Authorities and other geographies, 2016 https://www.gov.uk/government/ statistics/2011-rural-urban-classification-of-local-authority-andother-higher-level-geographies-for-statistical-purposes.

25. Morbey RA, Elliot AJ, Charlett A, et al. Development and refinement of new statistical methods for enhanced syndromic surveillance during the 2012 Olympic and Paralympic Games. Health Informatics J 2015;21:159-69. 1460458213517577.

26. Ross AM, Corden JM, Fleming DM, et al. The role of oak pollen in hay fever consultations in general practice and the factors influencing patients' decisions to consult. $\mathrm{Br} J$ Gen Pract 1996;46:451-5

27. Kilpeläinen $\mathrm{M}$, Terho $\mathrm{EO}$, Helenius $\mathrm{H}$, et al. Body mass index and physical activity in relation to asthma and atopic diseases in young adults. Respir Med 2006;100:1518-25.

28. Davies RJ, Rusznak C, Devalia JL, et al. Why is allergy increasing?-environmental factors. Clin Exp Allergy 1998;28 Suppl 6:8-14.

29. Bråbäck L, Hjern A, Rasmussen F, et al. Social class in asthma and allergic rhinitis: a national cohort study over three decades. Eur Respir J 2005;26:1064-8.

30. Hammer-Helmich L, Linneberg A, Thomsen SF, et al. Association between parental socioeconomic position and prevalence of asthma, atopic eczema and hay fever in children. Scand J Public Health 2014;42:120-7.

31. Perkin MR, Strachan DP. Which aspects of the farming lifestyle explain the inverse association with childhood allergy? J Allergy Clin Immunol 2006;117:1374-81.

32. Heinrich J, Wichmann HE. Traffic related pollutants in Europe and their effect on allergic disease. Curr Opin Allergy Clin Immunol 2004;4:341-8.

33. Linneberg A. Hypothesis: urbanization and the allergy epidemic--a reverse case of immunotherapy? Allergy 2005;60:538-9.

34. Ziello C, Sparks TH, Estrella N, et al. Changes to airborne pollen counts across Europe. PLoS One 2012;7:e34076. 